Article

\title{
Study on the Effect of Structure Parameters on NO Oxidation in DBD Reactor under Oxygen-Enriched Condition
}

\author{
Yunkai Cai * ${ }^{\mathbb{D}}$, Lin Lu and Peng Li \\ Marine Engineering, School of Energy and Power Engineering, Wuhan University of Technology, \\ Wuhan 430070, China; lulinwhut@whut.edu.cn (L.L.); leepeng@whut.edu.cn (P.L.) \\ * Correspondence: caiyunkai@whut.edu.cn; Tel.: +86-1562-372-3935
}

Received: 4 September 2020; Accepted: 24 September 2020; Published: 27 September 2020

check for updates

\begin{abstract}
To improve NO oxidation and energy efficiency, the effect of dielectric barrier discharge reactor structure on $\mathrm{NO}$ oxidation was studied experimentally in simulated diesel exhaust at atmospheric pressure. The mixture of $15 \% \mathrm{O}_{2} / \mathrm{N}_{2}$ (balance)/860 ppm $\mathrm{NO}_{\mathrm{X}}\left(92 \% \mathrm{NO}+8 \% \mathrm{NO}_{2}\right)$ was used as simulated diesel exhaust. The results show that DBD reactor with 100-mm electrode length has the highest oxidation degree of $\mathrm{NO}_{\mathrm{X}}$ and energy efficiency. $\mathrm{NO}$ oxidation efficiency is promoted and the generation of $\mathrm{NO}$ is inhibited significantly by increasing the inner electrode diameter. Increasing the inner electrode diameter not only improve the $\mathrm{E} / \mathrm{N}$, but also makes the distribution of $\mathrm{E} / \mathrm{N}$ more concentrated in the gas gap. The secondary electron emission coefficient $(\gamma)$ of electrode material is closely related to electron energy and cannot be considered as a constant, which causes the different performance of electrode material for NO oxidation under different gas gap conditions. Compared with the rod electrode, the screw electrode has a higher electric field strength near the top of the screw, which promotes the generation of $\mathrm{N}$ radicals and inhibits the generation of $\mathrm{O}$ radicals. Rod electrode has a higher NO oxidation and energy efficiency than screw electrode under oxygen-enriched condition.
\end{abstract}

Keywords: dielectric barrier discharge; $\mathrm{NO}$ oxidation; diesel exhaust; oxidation degree of $\mathrm{NO}_{\mathrm{X}}$

\section{Introduction}

Ocean transportation undertakes more than $90 \%$ of the global freight transportation which has the advantages of low cost and high security [1]. Furthermore, ships generally use diesel engines as their main propulsion devices. Sometimes, high-sulfur oil is used as the alternative fuel in marine diesel engines for lower shipping costs. As a result, their exhaust emissions cause serious air pollutions [2-4]. To control the exhaust pollution of marine diesel engine, the International Maritime Organization (IMO) regulated the emission of $\mathrm{NO}_{X}$ and $\mathrm{SO}_{X}$ from marine diesel engine exhaust, as shown in Figure $1[5,6]$.

For $\mathrm{SO}_{\mathrm{X}}$ removal, wet scrubbing can achieve a higher removal efficiency (more than 95\%), while, for $\mathrm{NO}_{X}$ removal, wet scrubbing has a low removal efficiency. This because more than $90 \%$ of $\mathrm{NO}_{\mathrm{X}}$ in the exhaust gas of marine diesel engine is $\mathrm{NO}$, and $\mathrm{NO}$ has low solubility in water and does not react with alkali solution. Some studies have shown that $\mathrm{NO}_{2}$ can promote the absorption of $\mathrm{NO}$ by alkaline solution. When the oxidation degree of $\mathrm{NO}_{\mathrm{X}}$ is increased to $\sim 50 \%$, the absorption efficiency of $\mathrm{NO}_{X}$ by alkaline solution is the highest [7]. The technology of wet desulfurization and denitrification is easy to integrate with existing desulfurization scrubber, reducing the investment and space, which will be an important development trend in the future [4]. Therefore, non-thermal plasma (NTP) oxidation combined with wet scrubbing for simultaneous desulfurization and denitrification was widely studied [8-10]. Compared to electron beam (EB) and corona discharge (CD), dielectric barrier 
discharge (DBD) has higher NO removal efficiency at lower specific energy density (SED) and shorter residence time [11]. There are many types of DBD, such as volume dielectric barrier discharge (VDBD), surface dielectric barrier discharge (SDBD) and diffuse coplanar surface barrier discharge (DCSBD) $[12,13]$. SDBD and DCSBD were widely used for surface modification. The VDBD reactor was widely used for the treatment of $\mathrm{NO}_{X}$ and $\mathrm{SO}_{X}$. The structure parameters of DBD reactor have great impact on NO removal efficiency and energy consumption, which has become a research hotspot [14-19].

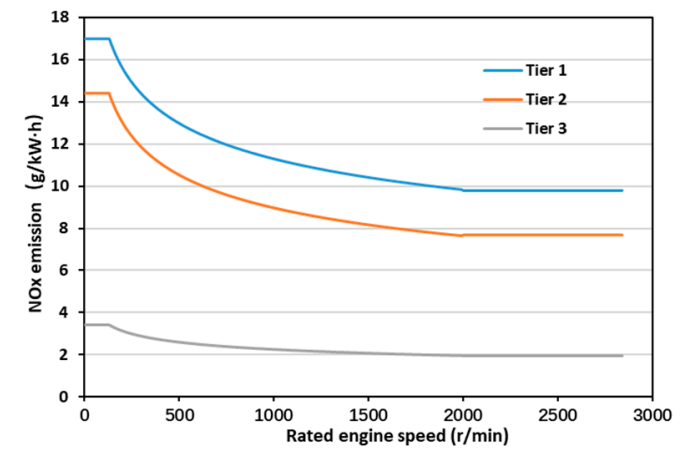

(a)

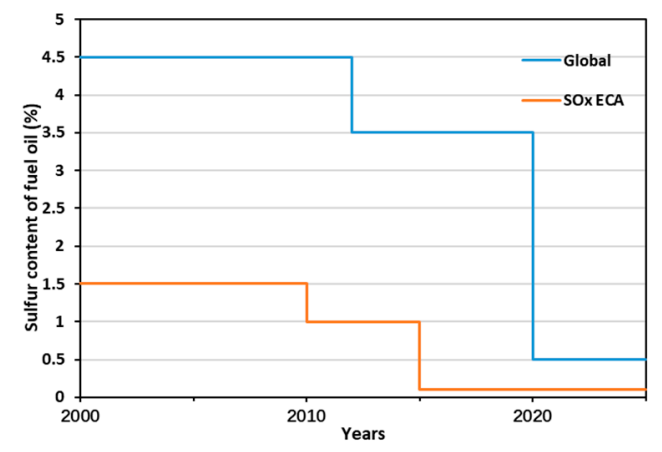

(b)

Figure 1. (a) Regulation of $\mathrm{NO}_{X}$ emission; and (b) regulation of $\mathrm{SO}_{X}$ emission. ECA, emission control area. Tier 1 took effect in 2000, Tier 2 in 2011 and Tier 3 in 2016.

In 2011 and 2012, Wanget al. studied the effect of inner electrode shape on discharge of DBD reactor. They showed that the DBD reactor with multineedle-to-cylinder electrode had better discharge performance than the regular DBD reactor [14,15]. In 2012 and 2013, Wang et al. used the mixture of $\mathrm{NO}$ and $\mathrm{N}_{2}$ to simulate the exhaust gas. The effects of electrode shape, electrode material and barrier medium thickness on NO removal were studied. They showed that tungsten electrode has a higher NO removal efficiency than copper and stainless-steel electrode with the same SED, which has a higher secondary electron emission coefficient. Screw electrode has a higher NO removal efficiency than rod electrodes, due to the smaller air gap capacitance, which makes the driving power of DBD reactor lower and dielectric loss lower [16,17]. In 2015 and 2016, Anaghizi and Talebizadeh et al. used the mixture of $\mathrm{NO}$ and $\mathrm{N}_{2}$ as the simulated diesel exhaust. The effects of electrode length, electrode material and electrode diameter on $\mathrm{NO}$ removal were studied [18,19].

Although the structure of DBD reactor has been studied in many previous investigations, most denitrification was carried out under the condition of $\mathrm{NO}_{X} / \mathrm{N}_{2}$. In such circumstance, $\mathrm{NO}_{X}$ is mainly removed by reduction reaction. However, the real exhaust gas contains a large amount of $\mathrm{O}_{2}$, which makes the reduction effect of $\mathrm{NO}_{X}$ by collision with $\mathrm{N}$ radicals ignorable. $\mathrm{NO}_{X}$ mainly reacts with $\mathrm{O}, \mathrm{OH}, \mathrm{HO}_{2}$ and other radicals produced by $\mathrm{O}_{2}$ and $\mathrm{H}_{2} \mathrm{O}$ and needs wet scrubber for complete removal [20]. There are few studies on the effect of DBD reactor structure parameters on NO oxidation under oxygen-enriched condition. Therefore, this study used $860 \mathrm{ppm} \mathrm{NO}\left(92 \% \mathrm{NO}+8 \% \mathrm{NO}_{2}\right) / 15 \%$ $\mathrm{O}_{2} / \mathrm{N}_{2}$ (balance) mixture as the simulated diesel exhaust gas. The effects of DBD structure parameters (such as electrode length, inner electrode diameter, inner electrode material and inner electrode shape) on NO oxidation performance were investigated. Supply voltage and discharge power were measured as well.

\section{Experiment and Methods}

\subsection{Experiment Setup}

The schematic diagram of the experimental system is shown in Figure 2. The gas flow of each component is controlled by the mass flow controller (MFC) and mixed uniformly by the gas mixer before entering the DBD reactor. The exhaust gas after DBD treatment is absorbed by alkali liquor, 
which reduces the damage to the environment. The concentrations of $\mathrm{NO}, \mathrm{NO}_{2}$ and $\mathrm{O}_{2}$ were measured by flue gas analyzer (Horiba PG-350). The total gas flow rate is $5 \mathrm{~L} / \mathrm{min}$ and the gas temperature is $25^{\circ} \mathrm{C}$.

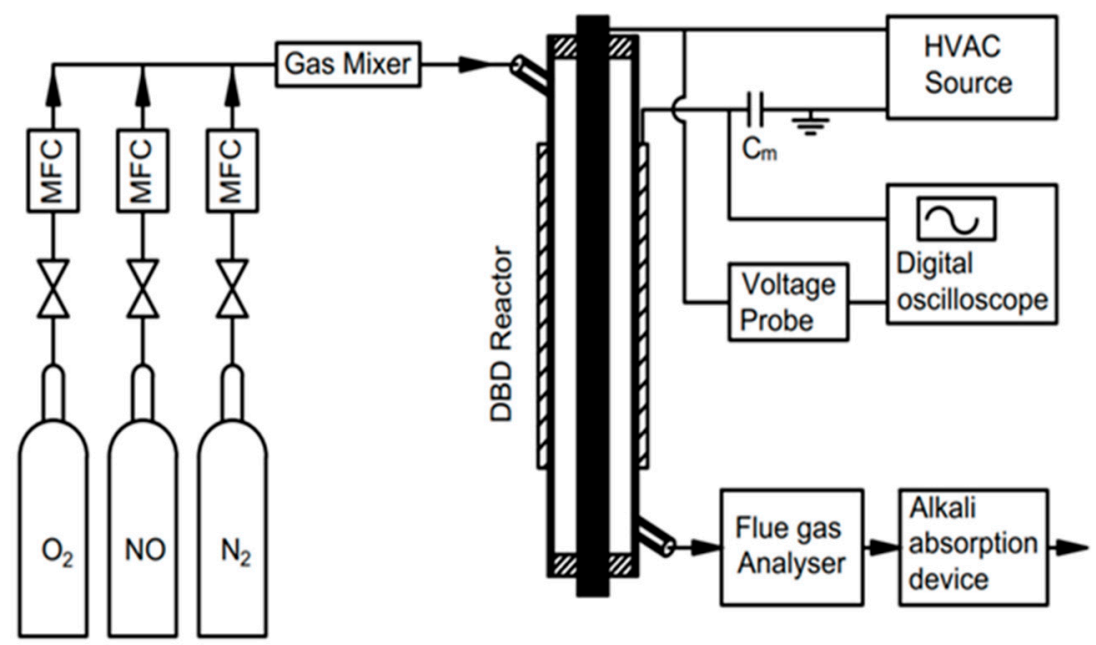

Figure 2. The schematic diagram of the experimental setup.

The high voltage AC (HVAC) power supply is used as the power supply of DBD reactor. The supply voltage used to generate plasma in the DBD reactor is within $0-25 \mathrm{kV}$ and discharge frequency is $10 \mathrm{kHz}$. The discharge power of DBD reactor is controlled by changing the supply voltage. The measurement capacitance $\left(C_{m}\right)$ of DBD discharge transmission charge is $0.47 \mu \mathrm{F}$, and the discharge voltage (voltage between inner and outer electrode) is decreased 1000 times by high voltage probe (TEK P6015A), which is input into oscilloscope. The discharge power is calculated by Lissajous figure. Figure 3 shows Lissajous figure obtained by digital oscilloscope (TEK TBS1052b).

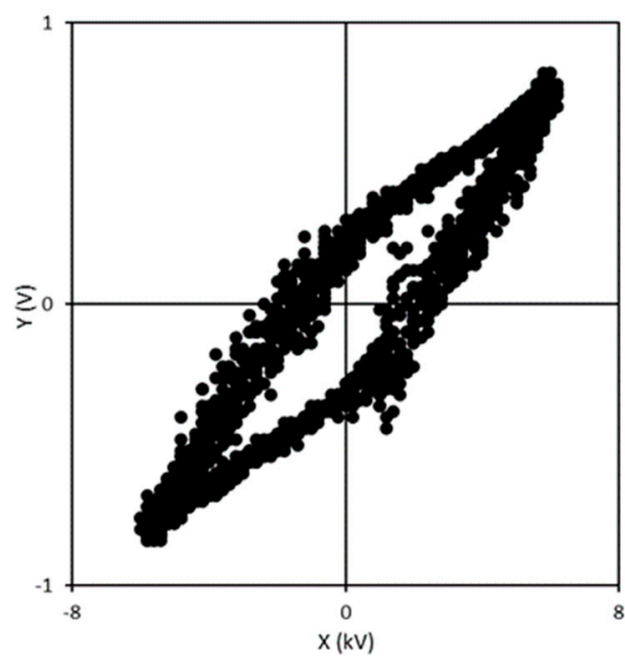

Figure 3. Lissajous figure obtained by digital oscilloscope (supply voltage $V_{P P}=14 \mathrm{kV}$, DBD reactor with inner electrode diameter $14 \mathrm{~mm}$, electrode length $100 \mathrm{~mm}$ ).

A cross-sectional view of DBD reactor and inner electrodes are shown in Figure 4. The DBD reactor is coaxial cylindrical, and the dielectric barrier is a quartz tube. The length of the quartz tube is $450 \mathrm{~mm}$, the outer diameter is $18 \mathrm{~mm}$, the inner diameter is $15 \mathrm{~mm}$ and the thickness is $1.5 \mathrm{~mm}$. The quartz tube is wrapped with copper foil as the outer electrode, and the length of discharge interval is adjusted by changing the length of copper foil. The materials making up the inner electrode are 
copper, stainless steel and aluminum with diameters of 10, 12 and $14 \mathrm{~mm}$. The shape of the inner electrode is rod or screw.

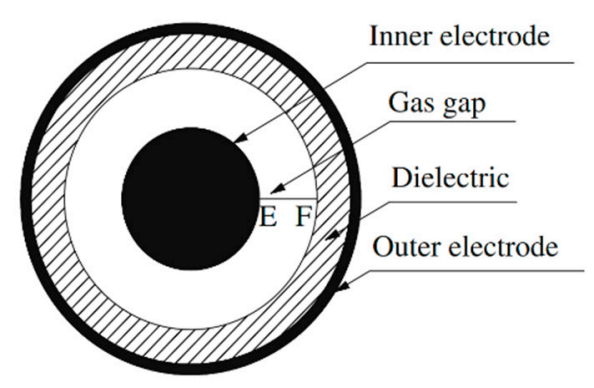

(a)

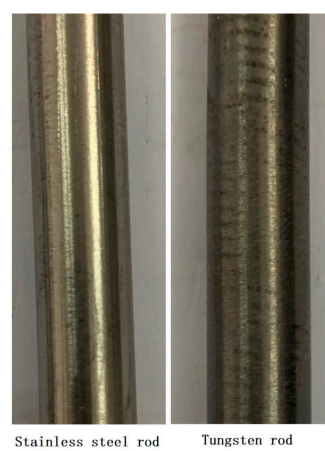

Stainless steel rod

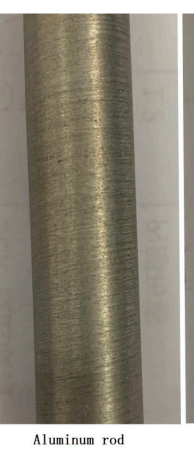

(b)

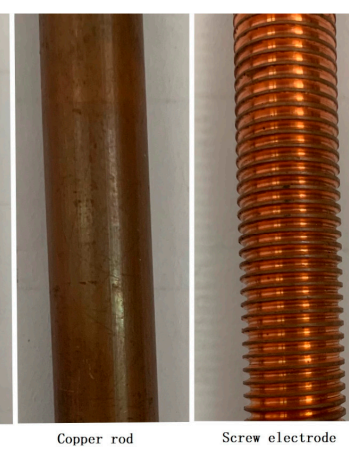

Screw electrode

Figure 4. (a) A cross-sectional view of the DBD reactor; and (b) the various inner electrodes used in the experiment.

\subsection{Evaluation Methods of NO Oxidation and Energy Efficiency}

In each test, the concentration of $\mathrm{NO}, \mathrm{NO}_{2}$ and $\mathrm{NO}_{\mathbf{X}}\left(\mathrm{NO}+\mathrm{NO}_{2}\right)$ were measured by gas analyzer for 30 times, as shown in Figure 5. The standard deviations of $\mathrm{NO}, \mathrm{NO}_{2}$ and $\mathrm{NO}_{\mathrm{X}}$ are 2.2, 3.3 and $1.8 \mathrm{ppm}$, respectively. The average concentrations of $\mathrm{NO}, \mathrm{NO}_{2}$ and $\mathrm{NOx}$ were taken as the final test results.

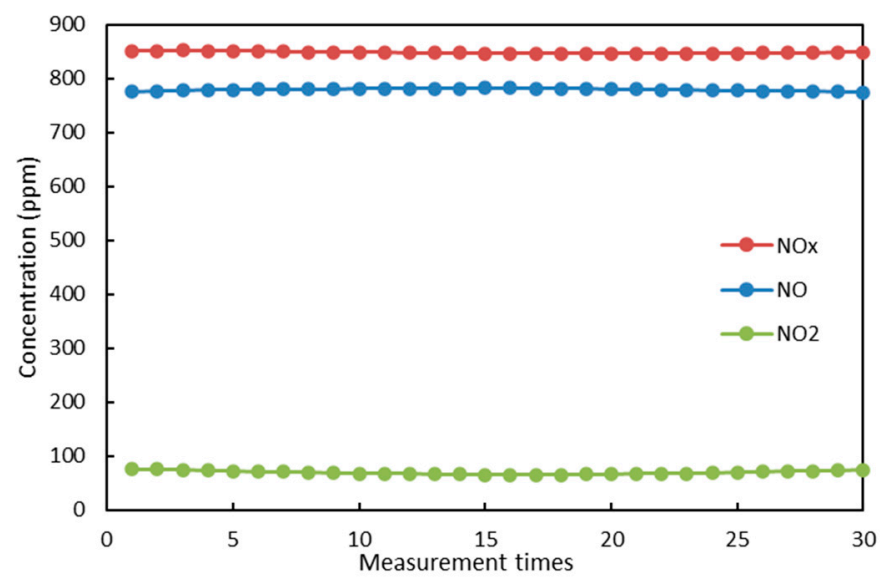

Figure 5. The concentration of $\mathrm{NO}, \mathrm{NO}_{2}$ and $\mathrm{NO}\left(\mathrm{NO}+\mathrm{NO}_{2}\right)$ measured by gas analyzer.

To explore the effect of DBD structure on $\mathrm{NO}$ oxidation, the oxidation degree of $\mathrm{NO}_{\mathrm{x}}$ was selected as the evaluation index. The oxidation degree of $\mathrm{NO}_{\mathrm{X}}$ is defined as follows:

$$
\alpha=\frac{\varphi\left(N O_{2}\right)}{\varphi\left(N O_{x}\right)} \times 100 \%
$$

where $\alpha$ is oxidation degree of $\mathrm{NO}_{\mathbf{X}} ; \varphi\left(\mathrm{NO}_{2}\right)$ is the concentration of $\mathrm{NO}_{2}, \mathrm{ppm}$; and $\varphi\left(N O_{x}\right)$ is the concentration of $\mathrm{NO}_{\mathrm{X}}, \mathrm{ppm}$. The discharge power was obtained by Lissajous figure (see Figure 3 ). The calculation of discharge power is given in Equation (2):

$$
P=f C_{m} K_{x} K_{y} K A,
$$


where $f$ is discharge frequency, $\mathrm{Hz} ; K_{x}$ is $\mathrm{x}$-axis sensitivity of oscilloscope, $\mathrm{V} /$ grid; $K_{y}$ is y-axis sensitivity of oscilloscope, V/grid; $K$ is voltage decrease ratio of high voltage probe, 1000:1; and $A$ is area enclosed by Lissajous figure. To evaluate the energy consumption level of DBD reactor, the specific energy density (SED) is defined as follows:

$$
S E D=\frac{P}{Q} \times 60,
$$

where $S E D$ is specific energy density, $\mathrm{J} / \mathrm{L} ; P$ is discharge power, $\mathrm{W}$; and $Q$ is gas flow, $\mathrm{L} / \mathrm{min}$.

\section{Results and Discussion}

\subsection{Effect of Electrode Length on NO Oxidation}

Figure 6 shows the effect of electrode length on NO oxidation under different SED. The experimental results show that the 100- and 150-mm electrodes have a higher oxidation degree of $\mathrm{NO}_{X}$ than $50-\mathrm{mm}$ electrode. The energy consumption is lower when the electrode length is $100 \mathrm{~mm}$. Electrode length determines the length of discharge interval, which mainly affects the residence time of gas in the discharge interval of DBD reactor $[18,21]$. Plasma chemical reaction is mainly divided into two stages. In the primary stage, the electrons are accelerated to form high-energy electrons by electric field in the discharge range, and the high-energy electrons collide with gas molecules leading to the ionization, excitation and dissociation of neutral molecules. In the secondary stage, free radicals, excited-state molecules and ions interact to cause radical-radical, radical-neutrals and ion-ion reactions in the downstream of the discharge range [22]. Therefore, the free radicals, excited molecules and atoms generated in the discharge range have a significant impact on pollutant removal. Under oxygenenriched condition, the concentration of oxidative radicals in the discharge range of DBD reactor gradually increased and reached equilibrium within several discharge cycles, and then it was basically stable with time [23]. It can be seen from the experimental results in Figure 6 that, when the electrode length is $50 \mathrm{~mm}$, the maximum oxidation degree of $\mathrm{NO}_{\mathrm{X}}$ is lower than that of electrode lengths 100 and $150 \mathrm{~mm}$ due to the short residence time of gas in DBD reactor, and the oxidation radicals do not reach the equilibrium concentration. When the electrode length is in the range of $100-150 \mathrm{~mm}$, the concentration of oxidation free radicals reaches equilibrium and does not change with the increase of discharge time. Increasing the electrode length does not lead to higher $\mathrm{NO}_{\mathrm{X}}$ oxidation degree, but higher energy consumption.

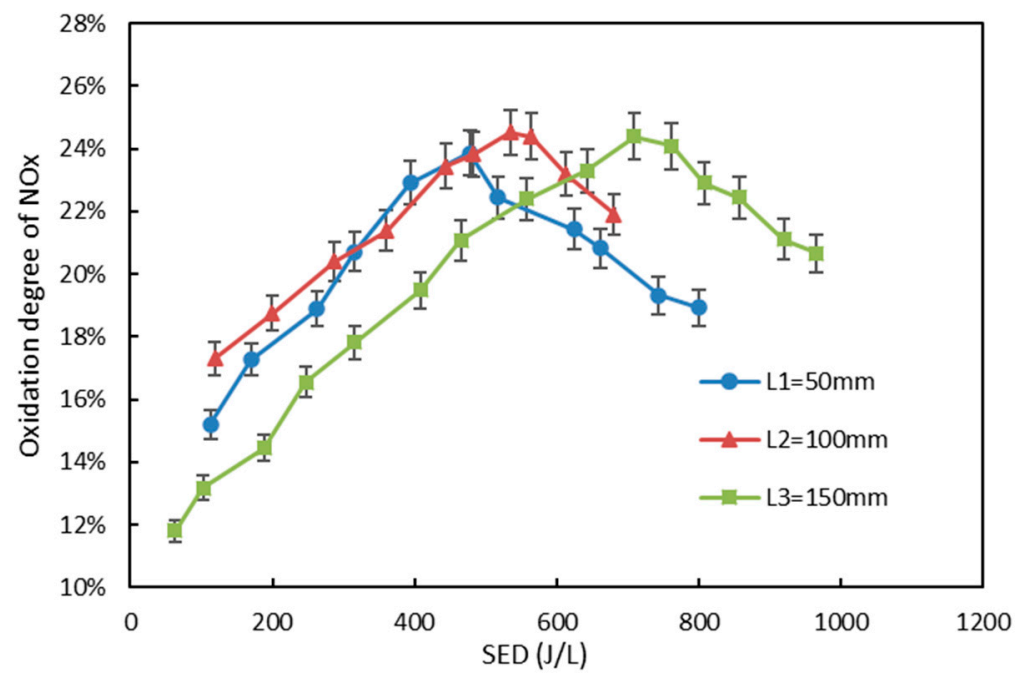

Figure 6. Effect of electrode length on oxidation degree of $\mathrm{NO}_{\mathrm{X}}$. 
It is worth noticing that the oxidation degree of $\mathrm{NO}_{X}$ rises first and then shows a decline trend with the increase of SED under oxygen-enriched condition, which is different from the $\mathrm{NO}_{\mathrm{X}}$ removal efficiency behavior under the condition of non-oxygen [19].

To analyze the mechanism, we measured the concentration changes of $\mathrm{NO}$ and $\mathrm{NO}_{2}$ in the process of NO oxidation in DBD reactor under oxygen-enriched condition. Figure 7 shows that the concentration of $\mathrm{NO}$ decreases first and then increases, while the concentration of $\mathrm{NO}_{2}$ increases first and then decreases with the increase of SED. The main plasma chemical reactions involved in oxygen enriched conditions are listed in Table 1.

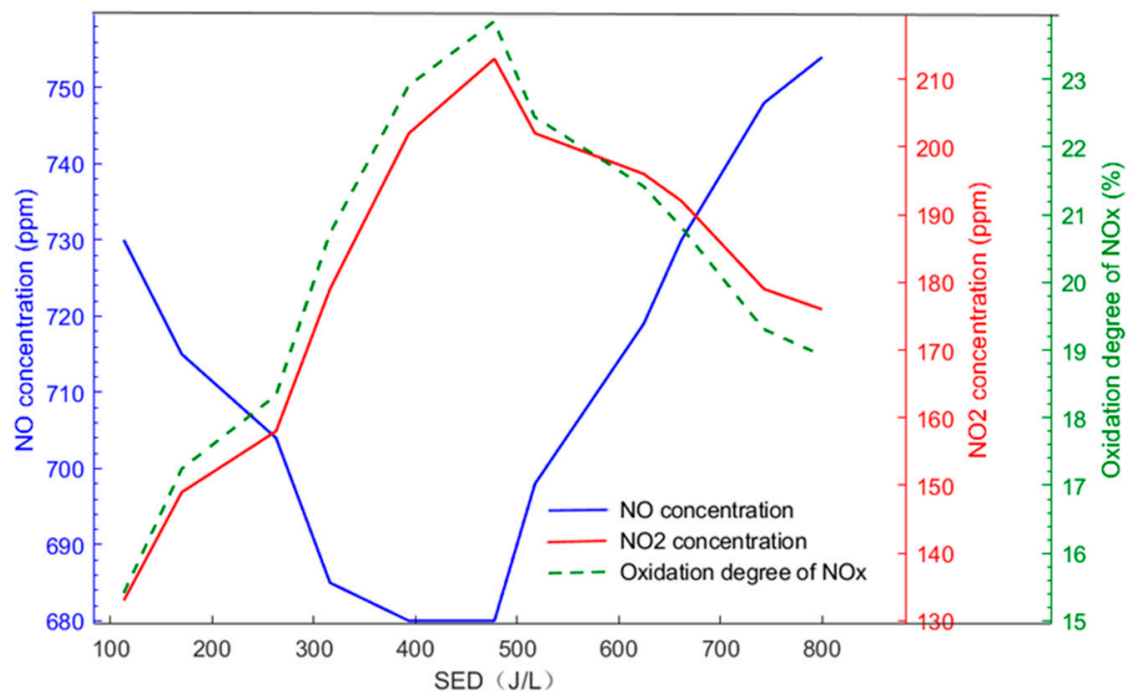

Figure 7. Change of $\mathrm{NO}$ and $\mathrm{NO}_{2}$ concentration during discharge under oxygen-enriched condition (electrode length $50 \mathrm{~mm}$ ).

Table 1. Main reactions and their rate coefficients.

\begin{tabular}{|c|c|c|c|}
\hline Reactions & NO. & Rate Coefficients $\left(\mathrm{cm}^{3} / \mathrm{s}\right.$ or $\left.\mathrm{cm}^{6} / \mathrm{s}\right)$ & References \\
\hline$e+N_{2}(X) \rightarrow e+N_{2}(X, v)$ & R1 & $f(E / N)$ & [24] \\
\hline$e+N_{2}(X) \rightarrow e+N_{2}\left(A^{3} \sum_{u}^{+}\right)$ & $\mathrm{R} 2$ & $f(E / N)$ & [25] \\
\hline$e+N_{2}(X) \rightarrow e+N+N$ & R3 & $f(E / N)$ & [25] \\
\hline$e+\mathrm{O}_{2} \rightarrow e+\mathrm{O}+\mathrm{O}$ & R4 & $f(E / N)$ & [26] \\
\hline$e+\mathrm{O}_{2} \rightarrow e+\mathrm{O}+\mathrm{O}\left({ }^{1} D\right)$ & R5 & $f(E / N)$ & [26] \\
\hline $\mathrm{O}+\mathrm{O}_{2}+\mathrm{N}_{2} \rightarrow \mathrm{O}_{3}+\mathrm{N}_{2}$ & R6 & $k=6.2 \times 10^{-34} \times\left(\frac{300}{T}\right)^{2}$ & [27] \\
\hline $\mathrm{O}+\mathrm{O}_{2}+\mathrm{O}_{2} \rightarrow \mathrm{O}_{3}+\mathrm{O}_{2}$ & R7 & $k=6.9 \times 10^{-34} \times\left(\frac{300}{T}\right)^{1.25}$ & [27] \\
\hline $\mathrm{O}_{3}+\mathrm{NO} \rightarrow \mathrm{NO}_{2}+\mathrm{O}_{2}$ & R8 & $k=1.4 \times 10^{-12} \times \exp \left(-\frac{1310}{T}\right)$ & [28] \\
\hline $\mathrm{O}+\mathrm{NO}+\mathrm{M} \rightarrow \mathrm{NO}_{2}+\mathrm{M}$ & R9 & $k=1.03 \times 10^{-30}\left(\frac{T}{298}\right)^{-2.87} \exp \left(\frac{780}{T}\right)$ & [28] \\
\hline $\mathrm{N}_{2}(X, v \geq 13)+\mathrm{O} \rightarrow \mathrm{NO}+\mathrm{N}$ & R10 & $k=1 \times 10^{-13}$ & [29] \\
\hline $\mathrm{N}+\mathrm{O}_{2} \rightarrow \mathrm{NO}+\mathrm{O}$ & R11 & $k=1.1 \times 10^{-14} \times T \times \exp \left(-\frac{3150}{T}\right)$ & [29] \\
\hline $\mathrm{N}_{2}\left(A^{3} \sum_{u}^{+}\right)+\mathrm{O}_{2} \rightarrow \mathrm{N}_{2}+\mathrm{O}+\mathrm{O}$ & R12 & $k=1.63 \times 10^{-12} \times\left(\frac{T}{300}\right)^{0.55}$ & [29] \\
\hline$N_{2}\left(A^{3} \sum_{u}^{+}\right)+O \rightarrow N O+N$ & R13 & $k=7 \times 10^{-12}$ & [29] \\
\hline $\mathrm{N}+\mathrm{O}+\mathrm{N}_{2} \rightarrow \mathrm{NO}+\mathrm{N}_{2}$ & R14 & $k=1.76 \times 10^{-31} \times T^{-0.5}$ & [29] \\
\hline $\mathrm{N}+\mathrm{O}_{3} \rightarrow \mathrm{NO}+\mathrm{O}_{2}$ & R15 & $k=5 \times 10^{-16}$ & [29] \\
\hline
\end{tabular}

The discharge voltage increases with the increase of SED, as shown in Figure 8a. As a result, the reduced electric field strength $\mathrm{E} / \mathrm{N}$ (ratio of the electric field strength to the gas particle number density) is increased (as shown in Figure 8b), which makes the mean electron energy increase [16]. 
Because the dissociation energy of $\mathrm{N}_{2}(9.8 \mathrm{eV})$ is higher than that of $\mathrm{O}_{2}(5.1 \mathrm{eV})$, the formation of $\mathrm{O}$ radicals is easier than that of $\mathrm{N}$ radicals in the process of plasma discharge [30]. $\mathrm{O}$ and $\mathrm{O}_{3}$ are generated firstly in the DBD reactor, which promote the oxidation of $\mathrm{NO}$ to $\mathrm{NO}_{2}$ via $\mathrm{R} 4-\mathrm{R} 9$ [26-28]. Therefore, the concentration of $\mathrm{NO}$ decreases, the concentration of $\mathrm{NO}_{2}$ increases and the oxidation degree of $\mathrm{NO}_{X}$ increases gradually with the increase of SED at the initial discharge stage.

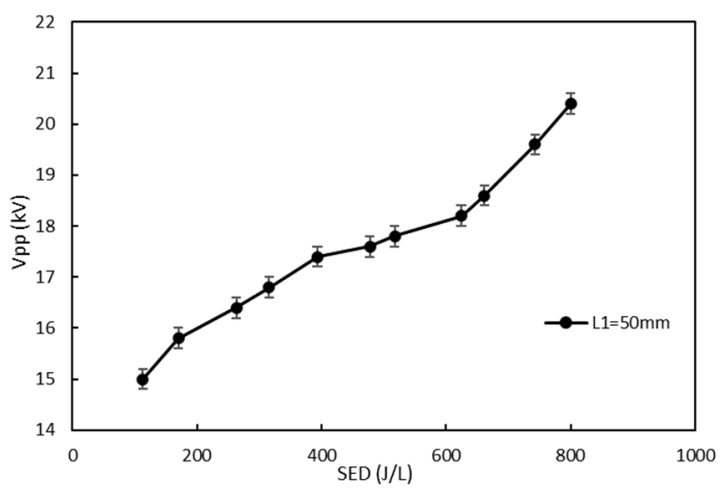

(a)

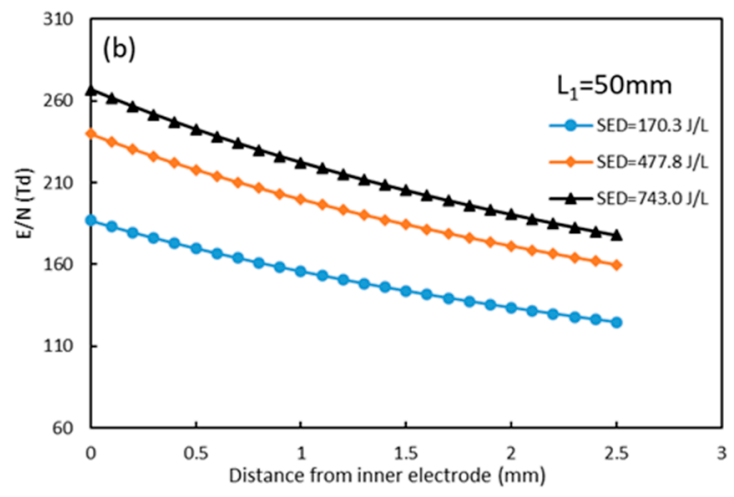

(b)

Figure 8. (a) The effect of SED on discharge voltage; and (b) the effect of SED on $E / N$ in gas gap of DBD reactor (electrode length is $50 \mathrm{~mm}$ and $V_{p p}$ means peak-to-peak voltage).

With the increase of SED, the E/N further increases, which promotes the dissociation of $\mathrm{N}_{2}$ to generate $\mathrm{N}$ radicals via $\mathrm{R} 3$, especially when the $\mathrm{E} / \mathrm{N}$ accesses $200 \mathrm{Td}$ [16]. Under oxygen-enriched condition, the $\mathrm{N}$ radicals will react with $\mathrm{O}, \mathrm{O}_{2}$ and $\mathrm{O}_{3}$ to generate $\mathrm{NO}$ via R11, R14 and R15 [29], which causes the increase of NO.

To analyze the effect of $\mathrm{E} / \mathrm{N}$ on the generation of radicals and excitation species in NTP process, BOLSIG + were used to calculate the electron energy distribution function (EEDF) and mean electron energy under different $\mathrm{E} / \mathrm{N}$ conditions. The electron Boltzmann equation (BE) in an ionized gas is [31]:

$$
\frac{\partial f}{\partial t}+v \cdot \nabla f-\frac{e}{m} E \cdot \nabla_{V} f=C[f]
$$

where $f$ is the electron distribution in six-dimensional phase space, $v$ are the velocity coordinates, $e$ is the elementary charge, $m$ is the electron mass, $E$ is the electric field, $\nabla_{V}$ is the velocity-gradient operator and $C$ represents the rate of change in $f$ due to collisions.

The mean electron energy was given by:

$$
\bar{\varepsilon}=\int_{0}^{\infty} \varepsilon^{3 / 2} f_{0} d \varepsilon
$$

where $\bar{\varepsilon}$ is the mean electron energy, $f_{0}$ is isotropic part of EEDF.

The rate coefficient related to electron collisions is defined as:

$$
k_{k}=\sqrt{\frac{2 e}{m}} \int_{0}^{\infty} \varepsilon \sigma_{k} f_{0} d \varepsilon
$$

where $\sigma_{k}$ is the cross section of collision process $k$. The electron-molecule collision cross sections are derived from LXCat [24-26].

The efficiency for a particular electron collision process can be calculated by [32]:

$$
G \text { value }=100 k /\left(v_{d} E / N\right)
$$


where $k$ is the rate coefficient of a particular electron collision process and $v_{d}$ is the drift velocity of electron. The $\mathrm{G}$ value represents the number of reactions per $100 \mathrm{eV}$ of input energy. The rate coefficient $k$ represents the number of reactions in a unit volume per unit time. The quantity $v_{d} E / N$ represents the amount of energy expended by the electrons in a unit volume per unit time.

The drift velocity $v_{d}$ can be calculated from the solution $f_{0}$ by Equation (8) [33]:

$$
v_{d}=-\frac{E}{3 N} \sqrt{\frac{2 e}{m}} \int_{0}^{\infty} \frac{\varepsilon}{Q} \frac{\partial f_{0}}{\partial \varepsilon} d \varepsilon
$$

where $Q$ is the effective total momentum-transfer cross section.

The simulation results are shown in Figure 9. Figure 9a shows the effect of E/N on mean electron energy. Obviously, the mean electron energy increases with the increase of E/N.

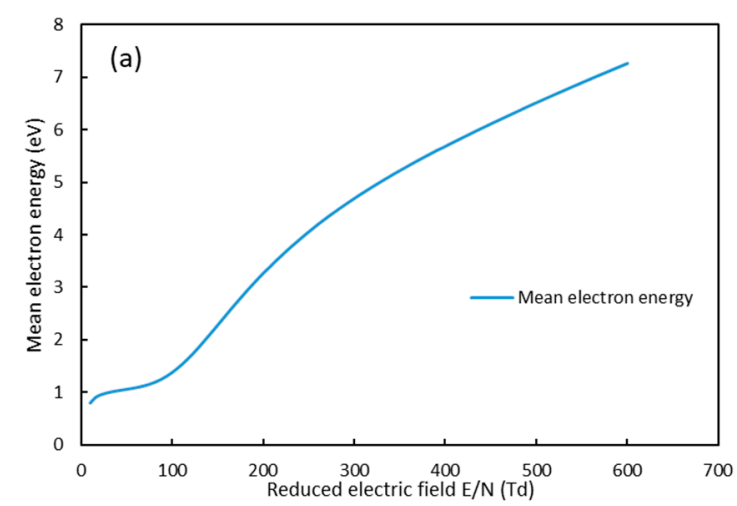

(a)

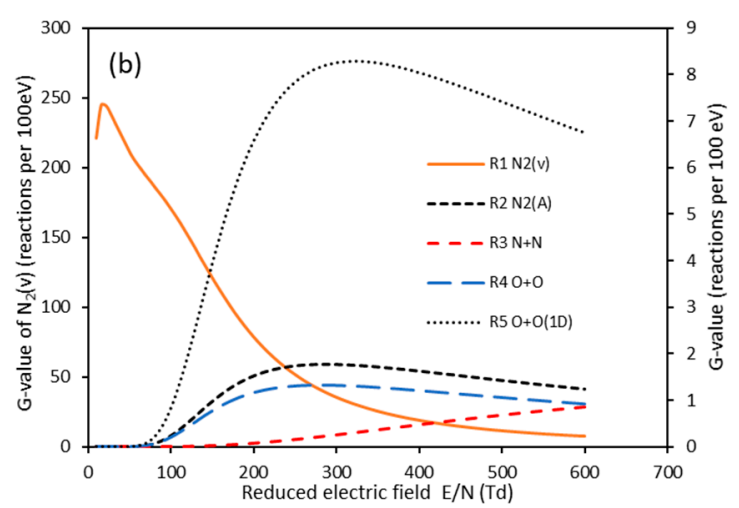

(b)

Figure 9. (a) The effect of E/N on mean electron energy; and (b) the effect of E/N on G-value of particularly reaction process (The G-value of reaction R1 is drawn separately on the left vertical axis).

Figure $9 \mathrm{~b}$ shows the effect of the $\mathrm{E} / \mathrm{N}$ on the efficiency for a particular electron collision process. The results show that the G-value of the reaction R1 for the generation of $N_{2}(X, v)$ (which has been proven to be an important species for the generation of NO via R10 and R11 [34]) decreases rapidly with the increase of $\mathrm{E} / \mathrm{N}$. The G-values of the main reactions $\mathrm{R} 4$ and $\mathrm{R} 5$ for the generation of $\mathrm{O}$ radicals increase rapidly in the range of $100-250 \mathrm{Td}$. As a result, $\mathrm{NO}$ is transformed to $\mathrm{NO}_{2}$ via $\mathrm{R} 8$ and $\mathrm{R} 9$, which causes the concentration of $\mathrm{NO}_{2}$ increases, and the oxidation degree of $\mathrm{NO}_{X}$ increases with the increase of SED at the initial discharge stage (as shown in Figures 6 and 7).

The $\mathrm{G}$-value of the reaction $\mathrm{R} 3$ for the generation of $\mathrm{N}$ radicals increases rapidly when $\mathrm{E} / \mathrm{N}$ exceeds $250 \mathrm{Td}$. Although the G-value of the reaction R2 for the formation of $N_{2}\left(A^{3} \sum_{u}^{+}\right)$(which was considered as an important species to generate NO via R13 [35]) decreases when E/N exceeds $250 \mathrm{Td}$, the generation efficiency of $\mathrm{NO}$ is higher due to the higher reaction rate coefficient of $\mathrm{N}$ for $\mathrm{NO}$ generation than that of $N_{2}\left(A^{3} \sum_{u}^{+}\right)[30,35,36]$. As a result, the generation efficiency of $\mathrm{O}$ radical decreases and the generation of $\mathrm{NO}$ increases when the $\mathrm{E} / \mathrm{N}$ exceeds $250 \mathrm{Td}$, which causes the oxidation degree of $\mathrm{NO}_{\mathrm{X}}$ to decrease with the increase of SED (as shown in Figures 6 and 7).

\subsection{Effect of Electrode Diameter on NO Oxidation}

Figure 10 shows the effect of electrode diameter on NO oxidation under different SED conditions. The experimental results show that increasing the electrode diameter can obtain higher oxidation degree of $\mathrm{NO}_{X}$ and reduce the energy consumption of DBD reactor. Increasing inner electrode diameter can reduce the gas gap of DBD reactor, which promotes the E/N of gas gap with the same supply voltage $[16,19]$. As $\mathrm{E} / \mathrm{N}$ increases, the mean electron energy increases as well; thus, increasing the inner electrode diameter makes it easier for $\mathrm{DBD}$ reactor to generate $\mathrm{O}$ radicals and promote NO oxidation. 


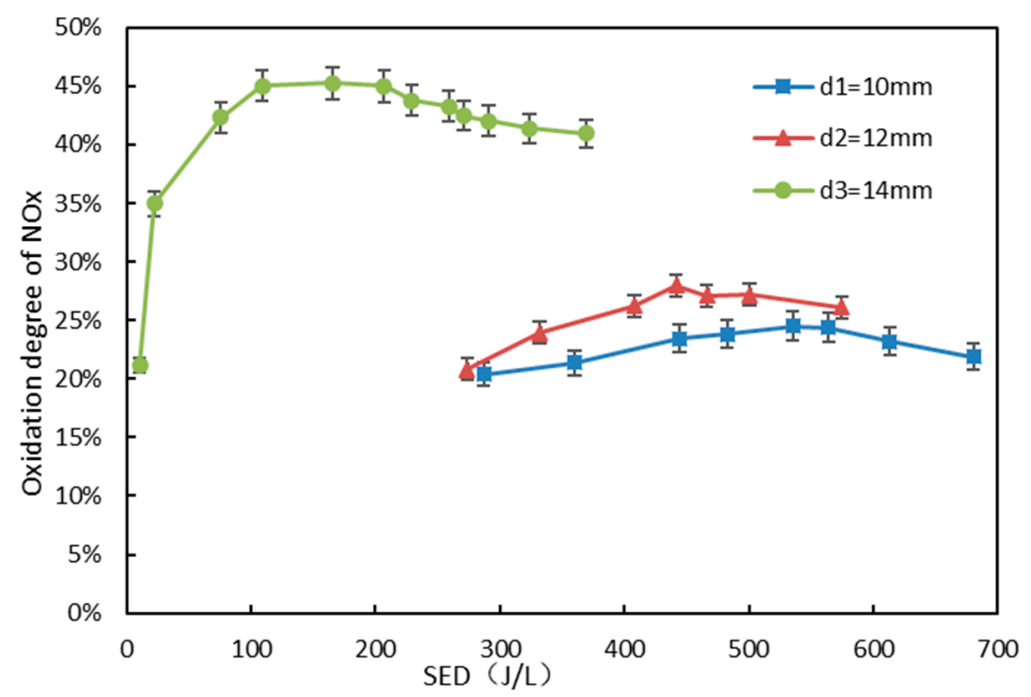

Figure 10. Effect of electrode diameter on oxidation degree of $\mathrm{NO}_{X}$ (electrode length is $100 \mathrm{~mm}$; inner electrode diameter is 10, 12 and $14 \mathrm{~mm}$; and gas gap is 2.5, 1.5 and $0.5 \mathrm{~mm}$, respectively).

Figure 11 shows the relationship between SED and discharge voltage for different electrode diameters. The results show that the discharge voltage decreases with the increase of inner electrode diameter under the same SED. The breakdown voltage $\left(U_{b}\right)$ of coaxial cylindrical DBD reactor can be calculated by the following formula [37]:

$$
U_{b}=\frac{B P d}{\ln \left(\frac{A P d}{1+\frac{1}{\gamma}}\right)}
$$

where $U_{b}$ is the gas breakdown voltage; $P$ is the gas pressure; $d$ is the distance between the electrodes; $\gamma$ is the secondary electron emission coefficient; and $A$ and $B$ are gas-related constants.

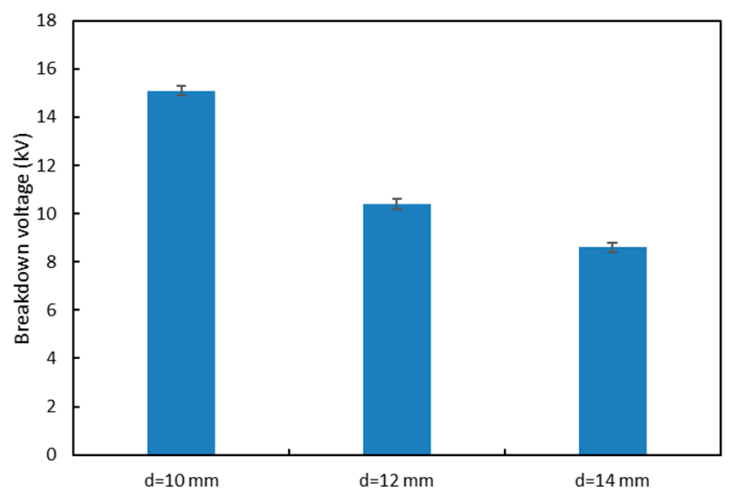

(a)

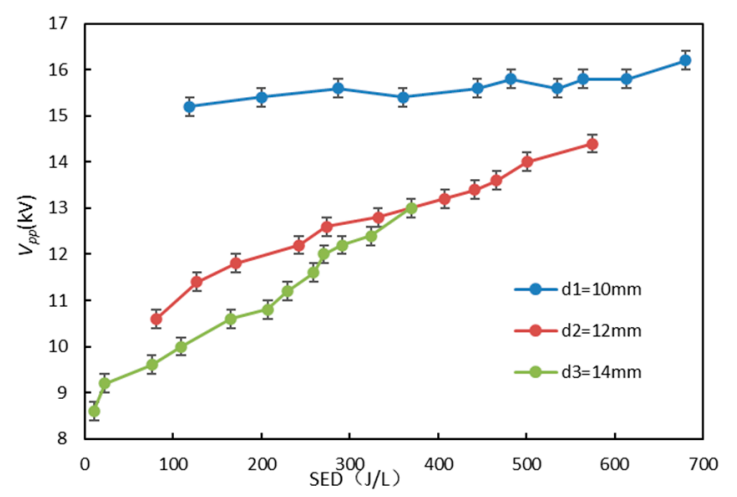

(b)

Figure 11. (a) The influence of electrode diameter on breakdown voltage; and (b) the relationship between SED and discharge voltage for different electrode diameters.

It can be seen from Equation (9) that increasing the diameter of the inner electrode can reduce the distance between the electrodes $(d)$, thus the breakdown voltage $\left(U_{b}\right)$ is reduced, as shown in Figure 11a. Increasing inner electrode diameter reduces the gas gap of DBD reactor and makes gas discharge easier. Therefore, the DBD reactor with smaller gas gap has better discharge performance 
and higher oxidation efficiency under the same SED [38]. In addition, according to the theory of Townsend discharge, the discharge current increases exponentially with the increase of gas gap [39]:

$$
I=I_{0} e^{a x}
$$

where $I$ is the discharge current; $I_{0}$ is the initial electron flow from the cathode; $x$ is the gas gap; and $a$ is the first Townsend ionization coefficient.

It can be seen from Equation (10) that the larger the gas gap $(x)$ has stronger electron avalanche effect and higher current growth rate [39]. Therefore, the DBD reactor with smaller the electrode diameter has a smaller discharge voltage change during the increase of SED, as shown in Figure 11b. This indicates that the DBD reactor with smaller electrode diameter needs to consume more SED to increase the discharge voltage and $\mathrm{E} / \mathrm{N}$. In addition, the stronger electron avalanche effect causes a greater heat loss of DBD reactor, which also increases the energy consumption. As a result, the energy efficiency of DBD reactor decreases with the decrease of electrode diameter.

However, it cannot accurately explain the experimental results only from the perspective of $\mathrm{E} / \mathrm{N}$ and electron avalanche. The increase of $\mathrm{E} / \mathrm{N}$ increases the electron energy, resulting in more $\mathrm{O}$ radicals, but also more $\mathrm{N}$ radicals. $\mathrm{N}$ radicals generate more $\mathrm{NO}$ via reactions $\mathrm{R} 11, \mathrm{R} 14$ and $\mathrm{R} 15$, which causes the increase of total $\mathrm{NO}_{X}$ concentration under oxygen-enriched condition. Comparing the change of $\mathrm{NO}_{X}$ concentration of DBD reactors with different electrode diameter during the discharge process (as shown in Figure 12), we can find that the $\mathrm{NO}_{\mathrm{X}}$ concentration at the outlet of DBD reactor with 14-mm electrode diameter is lower than that at the inlet during the whole discharge process, which indicates that increasing the electrode diameter can improve the production of $\mathrm{O}$ radicals and inhibit the generation of $\mathrm{NO}_{\mathrm{X}}$ at the same time.

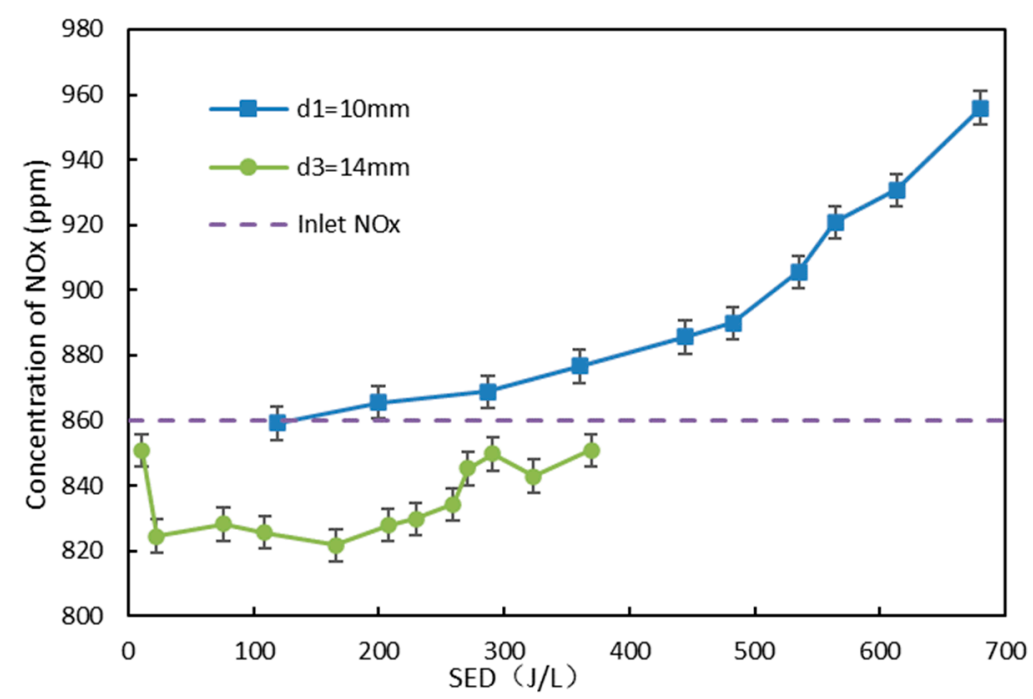

Figure 12. The change of $\mathrm{NO}_{X}$ concentration at the outlet of DBD reactor during the discharge.

To analyze the mechanism, the distribution of $\mathrm{E} / \mathrm{N}$ in the gas gap of DBD reactor with different inner electrode diameter was simulated, as shown in Figure 13. The simulation results show that E/N changes $(\Delta \mathrm{E} / \mathrm{N})$ in the gas gap of DBD reactors with 14-, 12- and 10-mm electrode diameter are 21.6, 51.8 and $68.5 \mathrm{Td}$, respectively. Increasing the electrode diameter does not simply improve the $\mathrm{E} / \mathrm{N}$, but also makes the distribution of $\mathrm{E} / \mathrm{N}$ more centralized, which makes it easier for DBD reactor to operate at high $\mathrm{O}$ radical generation efficiency. It is difficult for the DBD reactor with 10-mm electrode diameter to inhibit the generation of $N_{2}(X, v \geq 13)$ and $N$ radicals simultaneously due to the large $\Delta \mathrm{E} / \mathrm{N}$ in the gas gap. Therefore, the $\mathrm{DBD}$ reactor with $10-\mathrm{mm}$ electrode diameter is easier to generation $\mathrm{NO}_{X}$ and has a lower NO oxidation efficiency. 


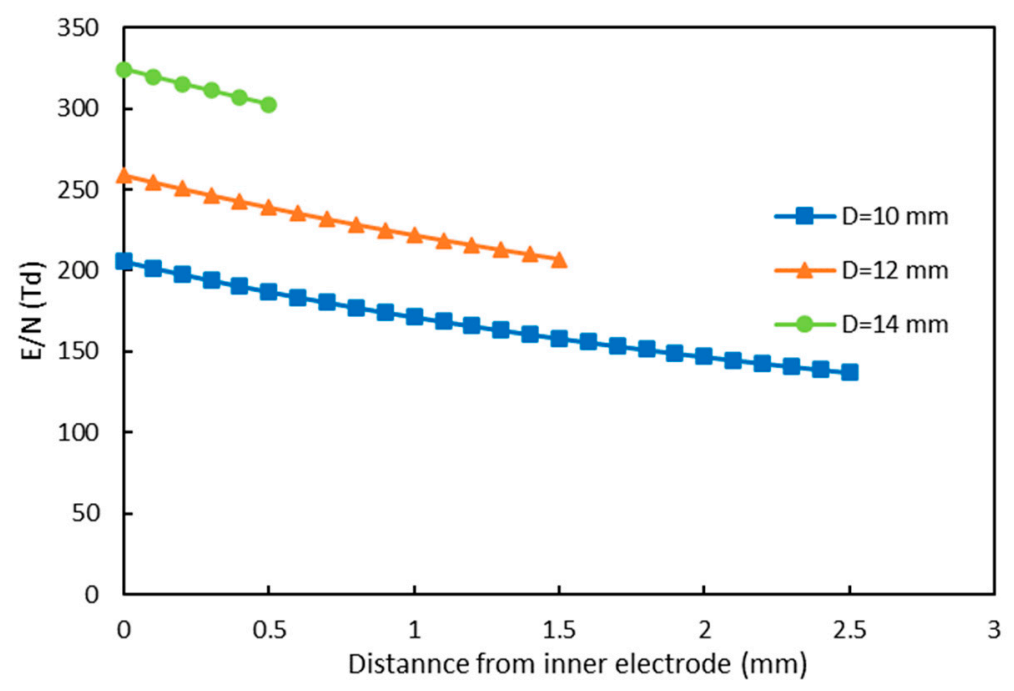

Figure 13. Distribution of $\mathrm{E} / \mathrm{N}$ in gas gap of $\mathrm{DBD}$ reactor with different inner electrode diameter (the $\mathrm{E} / \mathrm{N}$ of DBD reactor with different inner electrode diameter were calculated under their maximum oxidation degree of $\mathrm{NO}_{X}$ conditions).

\subsection{Effect of Inner Electrode Material}

Figure 14 shows the effect of electrode material on oxidation degree of $\mathrm{NO}_{X}$ in the DBD reactor with 10-mm electrode diameter (gas gap of $2.5 \mathrm{~mm}$ ). The results show that stainless-steel electrode has the best performance on $\mathrm{NO}$ oxidation and the highest energy efficiency. However, this experimental result is different from results of Wang and Talebizadeh, which indicate that aluminum and tungsten electrodes have higher NO removal and energy efficiency than copper and stainless-steel electrodes due to the higher secondary electron emission coefficients $\gamma[16,19] . \gamma$ is not a constant, which is related to the electron energy [40]. As a result, the performance of electrode material for NO treatment may also different under different $\mathrm{E} / \mathrm{N}$ conditions.

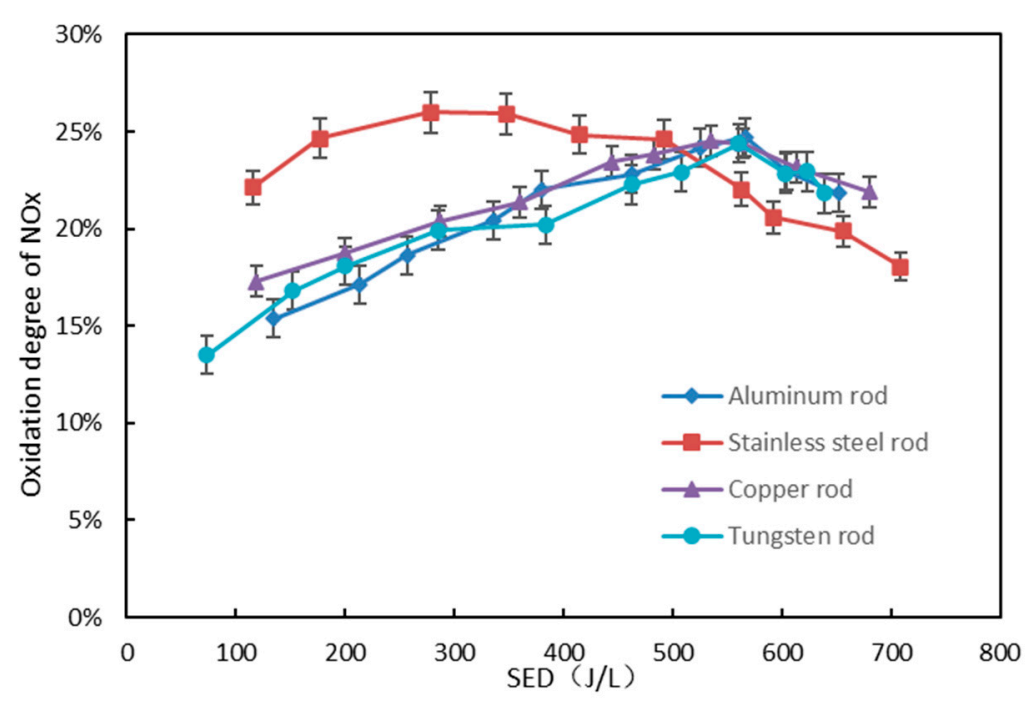

Figure 14. Effect of electrode materials on oxidation degree of NOX (electrode length is $100 \mathrm{~mm}$ and inner electrode diameter is $10 \mathrm{~mm}$ ).

Therefore, we experimentally studied the influence of electrode materials on NO oxidation in the DBD reactor with 14-mm electrode diameter (gas gap of $0.5 \mathrm{~mm}$ ), as shown in Figure 15 . The experimental results show that copper electrode has a higher NO oxidation and energy efficiency than stainless-steel electrode. Obviously, the performance of electrode material for NO oxidation is 
different under different gas gap condition. There is obvious interaction between gas gap and electrode material. The $\mathrm{E} / \mathrm{N}$ of the gas gap increases with the decrease of gas gap, which causes the increase of the mean electron energy [16]. Therefore, $\gamma$ of electrode material will change under different gas gaps, resulting in the interaction between gas gap and electrode material.

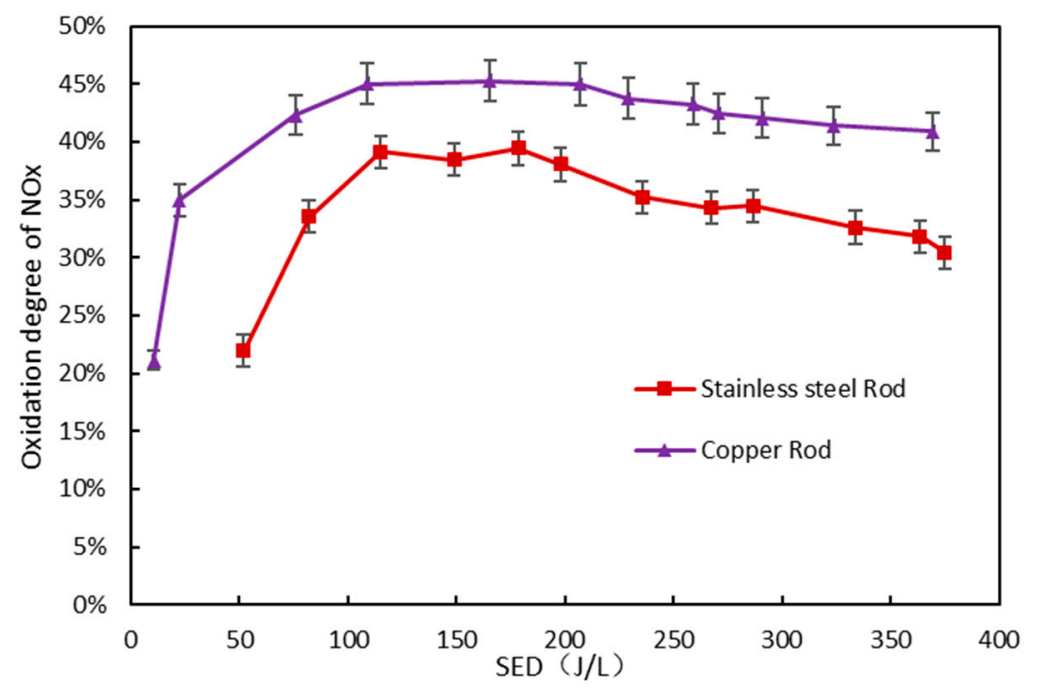

Figure 15. Effect of electrode materials on oxidation degree of $\mathrm{NO}_{\mathrm{X}}$ (electrode length is $100 \mathrm{~mm}$ and inner electrode diameter is $14 \mathrm{~mm}$ ).

\subsection{Effect of Inner Electrode Shape}

The effect of electrode shape on NO oxidation is shown in Figure 16. The results show that both the rod electrode and the screw electrode can make the oxidation degree of $\mathrm{NO}_{\mathrm{X}}$ reach $45 \%$. However, the energy efficiency of the rod electrode is higher. The experimental result is different from the result of Wang and Talebizadeh under $\mathrm{NO} / \mathrm{N}_{2}$ condition, as they showed screw electrode has a higher NO removal and energy efficiency $[16,18,19]$.

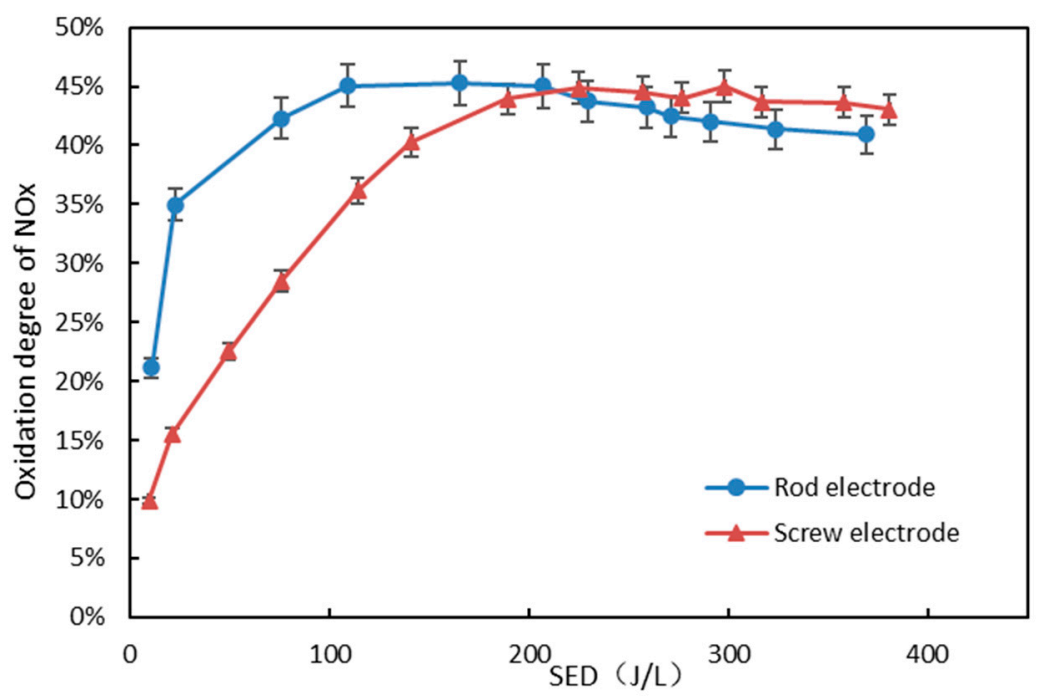

Figure 16. The effect of electrode shape on oxidation degree of $\mathrm{NO}_{X}$ under oxygen-enriched condition (electrode length is $100 \mathrm{~mm}$, diameter of round rod electrode is $14 \mathrm{~mm}$, diameter of external thread of threaded electrode is $14 \mathrm{~mm}$, pitch is $1.5 \mathrm{~mm}$ and thread depth is $1 \mathrm{~mm}$ ).

To explore the reasons, the $\mathrm{NO}, \mathrm{NO}_{2}$ and $\mathrm{NO}_{\mathrm{X}}$ concentration were measured during the discharge process, as shown in Figure 17. The experiment results show that screw electrode has a higher NO and 
$\mathrm{NO}_{\mathrm{X}}$ concentration and a lower $\mathrm{NO}_{2}$ concentration under the same SED. The distribution of $\mathrm{E}$ in the gas gap of DBD reactor with different inner electrode shape was simulated to analyze the mechanism, as shown in Figure 18. The simulation result shows that electric field strength (E) of the screw electrode near the top of the screw is much higher than the surface of rod electrode, which promotes the generation of $\mathrm{N}$ radical and the reduction efficiency of $\mathrm{NO}$ under $\mathrm{NO} / \mathrm{N}_{2}$ component [41]. However, the reduction of $\mathrm{NO}$ with $\mathrm{N}$ radicals is almost completely counterbalanced by the production of $\mathrm{NO}$ at $10 \% \mathrm{O}_{2}$ concentration [30,42]. Moreover, the high $\mathrm{E} / \mathrm{N}$ makes the generation efficiency of $\mathrm{O}$ radicals decrease, as shown in Figure $9 \mathrm{~b}$. As a result, the NO oxidation and energy efficiency of DBD reactor with screw electrode decreases under oxygen-enriched condition.

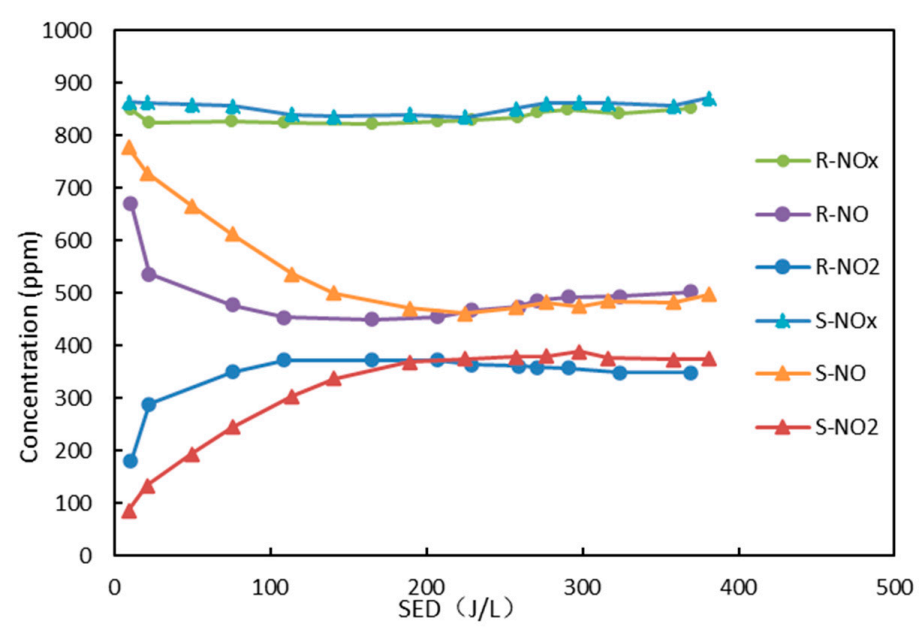

Figure 17. Effect of electrode shape on $\mathrm{NO}, \mathrm{NO}_{2}$ and $\mathrm{NO}_{\mathrm{X}}$ concentration ( $\mathrm{R}$ means, rod electrode; S, screw electrode).

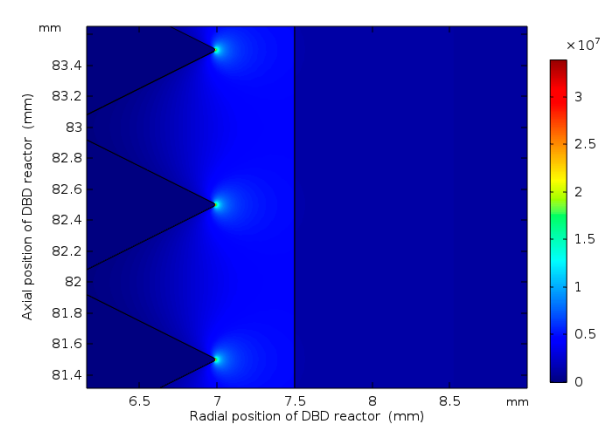

(a)

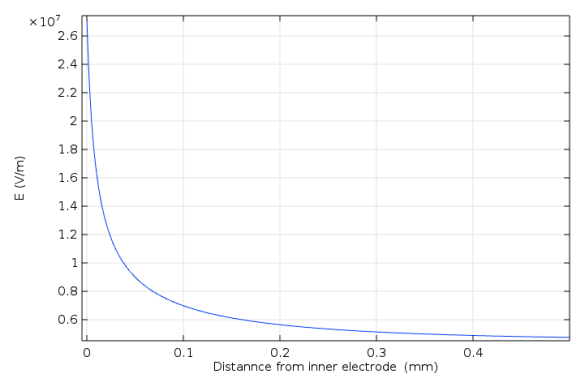

(c)

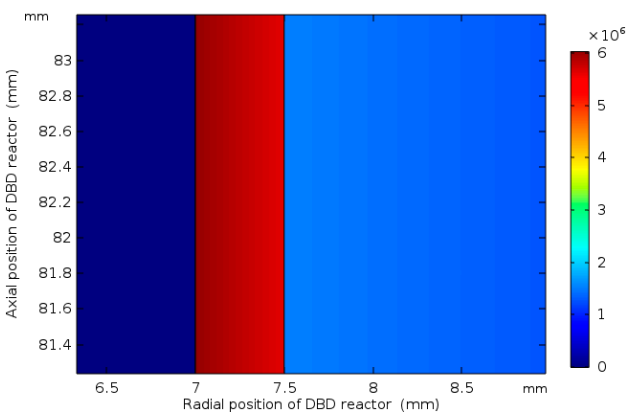

(b)

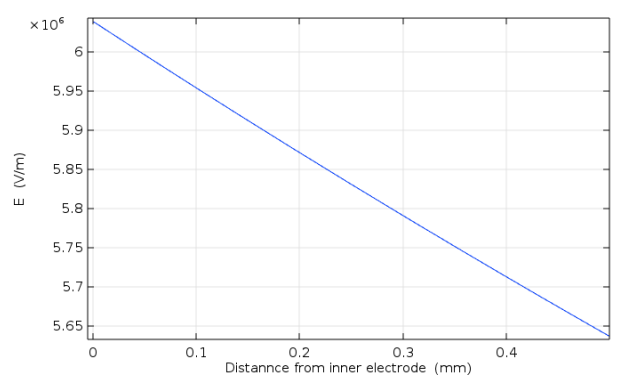

(d)

Figure 18. (a) Distribution of $\mathrm{E}$ in DBD reactor with screw electrode; (b) distribution of $\mathrm{E}$ in DBD reactor with rod electrode; (c) distribution of $\mathrm{E}$ in gas gap of DBD reactor with screw electrode; and (d) distribution of $\mathrm{E}$ in gas gap of DBD reactor with rod electrode. (Supply voltage is $5 \mathrm{kV}$, relative dielectric constant of the dielectric barrier is 3.7 and relative dielectric constant of the gas is 1.). 


\section{Conclusions}

This paper investigates the effect of DBD structure parameters on NO oxidation, including the effects of electrode length, electrode diameter, electrode material and electrode shape on discharge characteristics and NO oxidation. The experimental results show that there is an optimal electrode length for a certain flow of gas, which makes DBD reactor have the best performance on NO oxidation and energy efficiency. Too long electrode length cannot achieve higher $\mathrm{NO}_{X}$ oxidation degree, but increases the energy consumption of DBD reactor. The oxidation degree of $\mathrm{NO}_{X}$ increases first and then decreases with the increase of SED under oxygen-enriched condition, which is different from the experimental results that $\mathrm{NO}_{X}$ removal efficiency increases with the increase of SED under the condition of no oxygen. Increasing the diameter of inner electrode not only improves the $\mathrm{E} / \mathrm{N}$, but also makes the distribution of $\mathrm{E} / \mathrm{N}$ more concentrated in the gas gap, which promotes the oxidation and energy efficiency of DBD reactor. The performance of electrode material for NO oxidation is different under different gas gap condition, due to the change of $\mathrm{E} / \mathrm{N}$ and secondary electron emission coefficient $(\gamma)$. Compared with the rod electrode, the screw electrode has a higher electric field strength near the top of the screw, which promotes the generation of $\mathrm{N}$ radicals and inhibits the generation of $\mathrm{O}$ radicals. As a result, rod electrode has a higher NO oxidation and energy efficiency than screw electrode under oxygen-enriched condition.

Author Contributions: Conceptualization, Y.C. and L.L.; methodology, Y.C. and L.L.; software, Y.C.; validation, Y.C. and P.L.; investigation, Y.C.; resources, L.L.; data curation, Y.C.; writing-original draft preparation, Y.C.; writing-review and editing, Y.C., L.L. and P.L.; visualization, Y.C. and P.L.; supervision, L.L.; project administration, L.L.; and funding acquisition, L.L. All authors have read and agreed to the published version of the manuscript.

Funding: This research was funded by National Natural Science Foundation of China (NSFC), grant number 51679176.

Acknowledgments: The authors are thankful to all the personnel who either provided technical support or helped with data collection. We also acknowledge all the reviewers for their useful comments and suggestions.

Conflicts of Interest: The authors declare no conflict of interest.

\section{References}

1. Rahim, M.M.; Islam, T.; Kuruppu, S. Regulating global shipping corporations' accountability for reducing greenhouse gas emissions in the seas. Mar. Policy 2016, 69, 159-170. [CrossRef]

2. Boone, L. Reducing air pollution from marine vessels to mitigate arctic warming: Is it time to target black carbon? Carbon Clim. Law Rev. 2012, 6, 13-20. [CrossRef]

3. Francesco, D.N.; Claudia, C. Particulate matter in marine diesel engines exhausts: Emissions and control strategies. Transp. Res. D: Transp. Environ. 2015, 40, 166-191.

4. Fang, P.; Chen, X.B.; Tang, Z.J.; Huang, J.H.; Zeng, W.H.; Wu, H.W.; Tang, Z.X.; Cen, C.P. Current research status on air pollutant emission characteristics and control technology of marine diesel engine. Chem. Ind. Eng. Prog (China) 2017, 36, 1067-1076.

5. IMO. Nitrogen Oxides (NOx)—Regulation 13. 2019. Available online: https://www.imo.org/en/ourwork/ environment/pollutionprevention/airpollution/pages/nitrogen-oxides-(nox)-\%E2\%80\%93-regulation-13. aspx (accessed on 21 February 2019).

6. MO. Sulphur Oxides (SOx) and Particulate Matter (PM)-Regulation 14. 2019. Available online: http: //www.imo.org/en/OurWork/Environment/PollutionPrevention/AirPollution/Pages/Sulphur-oxides-(SOx) -\%E2\%80\%93-Regulation-14.aspx (accessed on 22 February 2019).

7. Fang, P.; Cen, C.; Tang, Z.; Zhong, P.; Chen, D.; Chen, Z. Simultaneous removal of SO2 and NOX by wet scrubbing using urea solution. Chem. Eng. J. 2011, 168, 52-59. [CrossRef]

8. Thagard, S.M.; Kinoshita, Y.; Ikeda, H.; Takashima, K.; Katsura, S.; Mizuno, A. Reduction for removal using wet-type plasma reactor. IEEE Trans. Ind. Appl. 2010, 46, 2165-2171. [CrossRef]

9. Lakshmipathiraj, P.; Chen, J.; Doi, M.; Takasu, N.; Kato, S.; Yamasaki, A.; Kojima, T. Electron beam treatment of gas stream containing high concentration of NOx: An in situ FTIR study. Chem. Eng. J. 2013, 229, 344-350. [CrossRef]

10. Wang, M.; Sun, Y.; Zhu, T. Removal of NOx, SO2, and Hg from simulated flue gas by plasma-absorption hybrid system. IEEE Trans. Plasma Sci. 2013, 41, 312-318. [CrossRef] 
11. Ma, S.; Zhao, Y.; Yang, J.; Zhang, S.; Zhang, J.; Zheng, C. Research progress of pollutants removal from coal-fired flue gas using non-thermal plasma. Renew. Sustain. Energy Rev. 2017, 67, 791-810. [CrossRef]

12. Zhao, Z.; Yang, D.; Wang, W.; Yuan, H.; Zhang, L.; Wang, S. Electrical characters and optical emission spectra of VBD coupled SBD excited by sine AC voltage in atmospheric air. Plasma Sci. Technol. 2017, 19, 064007. [CrossRef]

13. Shekargoftar, M.; Homola, T. A new approach to the crystallization of Perovskite films by cold hydrogen atmospheric pressure plasma. Plasma Chem. Plasma Process. 2020, 40, 539-548. [CrossRef]

14. Wang, X.; Yang, Q.; Yao, C.; Zhang, X.; Sun, C. Dielectric barrier discharge characteristics of multineedle-to-cylinder configuration. Energies 2011, 4, 2133-2150. [CrossRef]

15. Wang, X.; Yao, C.; Sun, C.; Yang, Q.; Zhang, X. Numerical modelling of mutual effect among nearby needles in a multi-needle configuration of an atmospheric air dielectric barrier discharge. Energies 2012, 5, 1433-1454. [CrossRef]

16. Wang, T.; Xiao, H.P.; Zeng, J.; Duan, E.; Li, C. Effect of reactor structure in DBD for nonthermal plasma processing of NO in N2 at ambient temperature. Plasma Chem. Plasma Process. 2012, 32, 1189-1201. [CrossRef]

17. Wang, T.; Sun, B.; Xiao, H. Kinetic analysis of dielectric layer thickness on nitric oxide removal by dielectric barrier discharge. Jpn. J. Appl. Phys. 2013, 52, 46201. [CrossRef]

18. Anaghizi, S.J.; Talebizadeh, P.; Rahimzadeh, H.; Ghomi, H. The configuration effects of electrode on the performance of dielectric barrier discharge reactor for NOx removal. IEEE Trans. Plasma Sci. 2015, 43, 1944-1953. [CrossRef]

19. Talebizadeh, P.; Rahimzadeh, H.; Anaghizi, S.J.; Ghomi, H.; Babaie, M.; Brown, R. Experimental study on the optimization of dielectric barrier discharge reactor for NOx treatment. IEEE Trans. Dielectr. Electr. Insul. 2016, 23, 3283-3293. [CrossRef]

20. Li, R.; Liu, X. Main fundamental gas reactions in denitrification and desulfurization from flue gas by non-thermal plasmas. Chem. Eng. Sci. 2000, 55, 2491-2506. [CrossRef]

21. Talebizadeh, P.; Rahimzadeh, H.; Babaie, M.; Anaghizi, S.J.; Ghomi, H.; Ahmadi, G.; Brown, R. Evaluation of residence time on nitrogen oxides removal in non-thermal plasma reactor. PLoS ONE 2015, 10, 0140897. [CrossRef]

22. Kim, H.H. Nonthermal plasma processing for air-pollution control: A historical review, current issues, and future prospects. Plasma Process. Polym. 2004, 1, 91-110. [CrossRef]

23. Wang, L.; Liu, Z.; Zhu, A.; Zhao, G.; Xu, Y. Numerical Simulation of.OH and HO2. radicals in dielectric barrier discharge plasmas. Acta Physico-Chimica Sinica 2008, 24, 1400-1404.

24. Biagi Database. Available online: www.lxcat.net (accessed on 7 July 2020).

25. Itikawa Database. Available online: www.lxcat.net/Itikawa (accessed on 28 June 2020).

26. TRINITI Database. Available online: www.lxcat.net/TRINITI (accessed on 26 June 2020).

27. Kossyi, I.A.; Kostinsky, A.Y.; A Matveyev, A.; Silakov, V.P. Kinetic scheme of the non-equilibrium discharge in nitrogen-oxygen mixtures. Plasma Sources Sci. Technol. 1992, 1, 207-220. [CrossRef]

28. NIST Chemical Kinetics Database. Available online: https://kinetics.nist.gov/kinetics/index.jsp (accessed on 26 June 2020).

29. Guerra, V.; Loureiro, J. Self-consistent electron and heavy-particle kinetics in a low-pressure-glow discharge. Plasma Sources Sci. Technol. 1997, 6, 373-385. [CrossRef]

30. Zhao, G.B.; Garikipati, S.V.B.J.; Hu, X.; Argyle, M.D.; Radosz, M. The effect of oxygen on nonthermal-plasma reactions of dilute nitrogen oxide mistures in N2. AIChE J. 2005, 51, 1813-1821. [CrossRef]

31. Hagelaar, G.J.M.; Pitchford, L.C. Solving the Boltzmann equation to obtain electron transport coefficients and rate coefficients for fluid models. Plasma Sources Sci. Technol. 2005, 14, 722-733. [CrossRef]

32. Penetrante, B.M.; Hsiao, M.C.; Merritt, B.T.; Vogtlin, G.E.; Wallman, P.H.; Neiger, M.; Wolf, O.; Hammer, T.; Bröer, S. Pulsed corona and dielectric-barrier discharge processing of NO in N2. Appl. Phys. Lett. 1996, 68, 3719-3721. [CrossRef]

33. Yoshida, K.; Goto, S.; Tagashira, H.; Winstead, C.; McKoy, B.V.; Morgan, W.L. Electron transport properties and collision cross sections in C[sub 2]F[sub 4]. J. Appl. Phys. 2002, 91, 2637-2647. [CrossRef]

34. Fridman, A. Plasma Chemistry, 1st ed.; Cambridge University Press: Cambridge, UK, 2008; pp. $355-362$.

35. Guerra, V.; Sá, P.A.; Loureiro, J. Role played by the N2(A3 $\Sigma u+)$ metastable in stationary N2and N2-O2discharges. J. Phys. D: Appl. Phys. 2001, 34, 1745-1755. [CrossRef] 


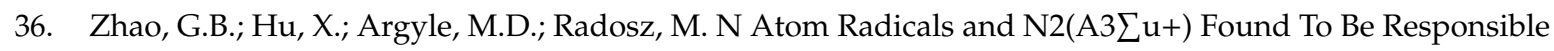
for Nitrogen Oxides Conversion in Nonthermal Nitrogen Plasma. Ind. Eng. Chem. Res. 2004, 43, 5077-5088. [CrossRef]

37. Latham, R.V. High Voltage Vacuum Insulation: Basic Concepts and Technological Practice, 1st ed.; Academic Press: London, UK, 1995.

38. Nemmich, S.; Tilmatine, A.; Dey, Z.; Hammadi, N.; Nassour, K.; Messal, S. Optimal Sizing of a DBD Ozone Generator Using Response Surface Modeling. Ozone: Sci. Eng. 2015, 37, 3-8. [CrossRef]

39. Zhao, Q.; Liu, S.; Tong, H. Plasma Technology and Its Applications, 1st ed.; National Defense Industry Press: Beijing, China, 2009.

40. Xu, X.; Zhu, D. Gas Discharge Physics, 1st ed.; Fudan University Press: Shanghai, China, 1996.

41. Sun, B.; Wang, T.; Yang, B.; Zhu, X.; Wang, D.; Xiao, H. Effect of Electrode Configuration on NO Removal in a Coaxial Dielectric Barrier Discharge Reactor. J. Chem. Eng. Jpn. 2013, 46, 746-750. [CrossRef]

42. Penetrante, B.M.; Bardsley, J.N.; Hsiao, M.C. Kinetic Analysis of Non-Thermal Plasmas Used for Pollution Control. Jpn. J. Appl. Phys. 1997, 36, 5007-5017. [CrossRef]

(C) 2020 by the authors. Licensee MDPI, Basel, Switzerland. This article is an open access article distributed under the terms and conditions of the Creative Commons Attribution (CC BY) license (http://creativecommons.org/licenses/by/4.0/). 